Old Dominion University

ODU Digital Commons

Community \& Environmental Health Faculty

Publications

Community \& Environmental Health

2020

\title{
WHO Infant and Young Child Feeding Indicators in Relation to Anthropometric Measurements
}

\author{
Abdullah Al-Taiar \\ Old Dominion University, aaltaiar@odu.edu \\ Nawal Alqaoud \\ Majeda S. Hammoud \\ Faheema Alanezi \\ Nawal Aldalmani
}

See next page for additional authors

Follow this and additional works at: https://digitalcommons.odu.edu/commhealth_fac_pubs

Part of the Community Health and Preventive Medicine Commons, and the International Public Health Commons

\section{Original Publication Citation}

Al-Taiar, A., Alqaoud, N., Hammoud, M. S., Alanezi, F., Aldalmani, N., \& Subhakaran, M. (2020). WHO infant and young child feeding indicators in relation to anthropometric measurements. Public Health Nutrition, 23(10), 1665-1676. doi:10.1017/S1368980019004634

This Article is brought to you for free and open access by the Community \& Environmental Health at ODU Digital Commons. It has been accepted for inclusion in Community \& Environmental Health Faculty Publications by an authorized administrator of ODU Digital Commons. For more information, please contact digitalcommons@odu.edu. 


\section{Authors}

Abdullah Al-Taiar, Nawal Alqaoud, Majeda S. Hammoud, Faheema Alanezi, Nawal Aldalmani, and Monica Subhakaran 


\title{
WHO infant and young child feeding indicators in relation to anthropometric measurements
}

\author{
Abdullah Al-Taiar ${ }^{1, *} \oplus$, Nawal Alqaoud ${ }^{2}$, Majeda S Hammoud ${ }^{3}$, Faheema Alanezi², \\ Nawal Aldalmani ${ }^{2}$ and Monica Subhakaran ${ }^{2}$ \\ 'School of Community \& Environmental Health, College of Health Sciences, Old Dominion University, Norfolk, VA \\ 23508, USA: ${ }^{2}$ Food and Nutrition Administration, Ministry of Health, Box 5, 13001 Kuwait City, Kuwait: ${ }^{3}$ Department \\ of Pediatrics, Faculty of Medicine, Kuwait University, Box 24923, Safat, 13110 Kuwait City, Kuwait
}

Submitted 23 February 2019: Final revision received 28 September 2019: Accepted 30 0ctober 2019: First published online 14 April 2020

\begin{abstract}
Objective: This study aimed to report the WHO infant and young child feeding (IYCF) indicators from Kuwait and to investigate the associations between these indicators and anthropometric measurements.

Design: The Kuwait Nutritional Surveillance System uses observational crosssectional approach to collects data by face-to-face interviews with mothers or child guardians using a structured questionnaire that was developed based on the WHO IYCF indicators. The weight and height of infants and young children were measured using digital scales in a standardised manner.

Setting: Vaccination centres in all governorates (provinces) of Kuwait.

Participants: Infants and young Kuwaiti children aged 0-23 months ( $N$ 5839).

Results: The prevalence of exclusive breastfeeding and age-appropriate breastfeeding were 8.0 and $7.4 \%$, respectively. The prevalence of stunting and wasting was 7.5 and $2.4 \%$, respectively, while the prevalence of overweight and obesity was 6.5 and $1.6 \%$, respectively. In the multivariable analysis, exclusive breastfeeding and age-appropriate breastfeeding were more common in children with stunted growth (AOR 1.71 (95\% CI 1.08, 2.70; $P=0.021$ ) and 1.44 (95\% CI $1.01,2 \cdot 06 ; P=0.046)$, respectively). The introduction of solid/semisolid or soft foods was inversely associated with stunting (AOR 0.52; $95 \%$ CI 0.30, 0.90; $P=0.021)$. Only age-appropriate breastfeeding was inversely associated with overweight (AOR 0.62; $95 \%$ CI 0.39, 0.98; $P=0.043$ ).

Conclusion: Our findings showed that indicators of breastfeeding are low in Kuwait. Our findings suggest that the associations between different WHO IYCF indicators and stunting as well as overweight is complex, which highlights the need for a better understanding of WHO IYCF indicators in both low- and high-income countries.
\end{abstract}

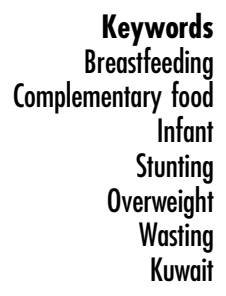

Poor nutrition in the first 2 years of life has significant implications on child morbidity ${ }^{(1,2)}$, mortality ${ }^{(3,4)}$ and cognitive development; additionally, poor nutrition increases the risk of chronic non-communicable diseases in adulthood $^{(5,6)}$. WHO recommends that, unless contraindicated, children should be exclusively breastfed for the first 6 months of life, followed by the introduction of complementary food alongside breastfeeding for up to 2 years or beyond ${ }^{(7)}$. Although this recommendation is widely acceptable, breastfeeding rates remained mostly low despite continued efforts to improve breastfeeding practices ${ }^{(8-10)}$. There are significant differences in breastfeeding indicators between low- and high-income countries. For example, studies have demonstrated an inverse association between breastfeeding at 6 months and the gross domestic product per person ${ }^{(8,11)}$.

The period from 6 to 23 months after birth, which is the transition time from exclusive breastfeeding to consuming a wide range of family foods while breastfeeding continues, is an extremely important time during which the largest proportion of stunting occurs ${ }^{(12)}$. During this period, children consume small amounts of foods, given their small gastric capacity; therefore, complementary foods need to have high nutrient density, and children need to be fed 
frequently to support optimal physical growth and brain development $^{(13)}$. As a result, it has been suggested that meeting the nutritional needs of children aged 6-23 months can be challenging, not only in resource-poor settings but also in high-income settings, which has significant implications on their growth and development ${ }^{(13,14)}$. On the other hand, the early introduction of complementary foods (before the age of 4 or 6 months), as well as particular types of foods have been proposed to be related to obesity later in life $\mathrm{l}^{(15-17)}$

In an effort to address the lack of standard indicators that assess feeding practices of infants and young children at national, regional and global levels, WHO published the infant and young child feeding (IYCF) indicators along with the technical details of their measurements and calculations ${ }^{(18,19)}$. These indicators, which address breastfeeding and complementary feeding, have allowed for meaningful comparisons between different countries and monitoring trends in IYCF practices over time. However, the ability of these indicators to predict anthropometric measurements and, in particular, stunting and underweight remain under intense debate.

WHO IYCF indicators have traditionally been obtained from demographic health surveys (DHS) in several lowand middle-income countries. Only a few high-income countries usually report on these indicators, making global comparisons difficult ${ }^{(8)}$. In Kuwait, as in other oil-rich Arab states in the Middle East, there is a lack of data on IYCF, and the global estimates of IYCF indicators in the Middle East and North Africa (MENA) region usually do not include data from these countries or include data from the Gulf Family Health Survey that was conducted more than a decade ago. The few reports that have published on IYCF practices in Kuwait ${ }^{(20)}$ did not follow WHO IYCF indicators, hampering global comparison.

Furthermore, similar to other high-income countries, childhood obesity has become a major public health problem in Kuwait; more than $45 \%$ of school children are either overweight or obese ${ }^{(21)}$. Studying IYCF practices, such as exclusive breastfeeding during the first 6 months of life and complementary feeding, is a prerequisite to improve these practices, hence combating obesity and overweight at an early stage (15-17,22). $^{\text {. }}$ In 2014, the Kuwait Nutritional Surveillance System (KNSS) was reviewed to assess the feeding practices of infants and young children according to WHO IYCF indicators. Over 3 consecutive years (2015-2017), data have accumulated and provide a unique opportunity to document feeding practices for infants and young children. In this study, we aimed, first, to characterise the current IYCF practices in Kuwait and, second, to investigate the associations between WHO IYCF indicators and overweight/obesity, as well as stunting in Kuwaiti children aged 0-23 months.

\section{Methods}

\section{Study participants}

The KNSS collects data from Kuwaiti citizens using structured data collection forms through personal interviews conducted by trained data collectors who are permanently employed for this purpose. The overall objective of KNSS is to provide regular and updated information on the nutritional status of the Kuwaiti population (children and adults) and the influencing factors. The system also aims to provide nationwide information on nutritional status trends in all age groups by tracking nutritional status over time. The KNSS was reviewed to collect data on IYCF practices using the WHO guidelines ${ }^{(18,19)}$.

Children aged $0-23$ months ( $<730 \mathrm{~d}$ of age) were recruited from health centres in all governorates of Kuwait at the time of their vaccination from January 2015 to December 2017. According to the vaccination schedule in Kuwait, children are vaccinated at birth; by the end of the 2nd, 3rd, 4th, 6th, 12th, 18th and 24th months after birth; and at the age of 3.5 years. Ideally, data should be collected through household surveys, a method that is probably not feasible in Kuwait. However, unlike other countries where vaccination coverage has been low, vaccination in Kuwait is free of charge and the coverage reaches almost $100 \%$. Thus, it is possible to assume that recruiting children from health centres will generate a representative sample of Kuwaiti children. The KNSS uses a list of health centres that are designated to be sentinel sites for surveillance in all governorates (provinces). No sampling method was used as every mother or child guardian attending the vaccination centres was invited to participate in data collection, and only less than $2 \%$ refused to participate.

\section{Data collection}

Table 1 includes the details of the core and optional indicators that we report in this study as per the WHO approach $^{(18,19)}$. This approach provides a clear guidance for data collection and calculation of IYCF indicators with an example of the questionnaire that should be adapted. According to this approach, except for the two indicators, 'early initiation of breastfeeding' and 'children ever breastfed', all indicators were based on the respondents' current status at the time of interview. In other words, mothers were not asked when they started or stopped a particular feeding practice; rather, they were asked to report their practices during the day and night before the interview. Following this approach, early initiation of breastfeeding was based on history recall from mothers of children aged 0-23 months who were put to the breast within $1 \mathrm{~h}$ of birth. Exclusive breastfeeding was defined considering infants $0-5$ months $(<183 \mathrm{~d}$ ) who were breastfed and received no liquids (except oral rehydration solution and/or vitamins/mineral supplements) or complementary 
Infant and young child feeding indicators

Table 1 WHO infant and young child feeding core and optional indicators ${ }^{(19)}$ targeted by the Kuwait Nutritional Surveillance System (2015-2017)

\begin{tabular}{|c|c|}
\hline \multicolumn{2}{|l|}{ Core indicators } \\
\hline Early initiation of breastfeeding & $\begin{array}{l}\text { Proportion of children born in the last } 24 \text { months who were } \\
\text { put to the breast within } 1 \mathrm{~h} \text { of birth or caesarean section }\end{array}$ \\
\hline Exclusive breastfeeding under 6 months & $\begin{array}{l}\text { Proportion of infants } 0-5 \text { months (i.e. }<183 \text { d) of age who } \\
\text { were fed exclusively breast milk during the previous day }\end{array}$ \\
\hline Continued breastfeeding at 1 year & $\begin{array}{l}\text { Proportion of children } 12-15 \text { months (i.e. } \geq 365 \text { to } \leq 487 \text { d) of } \\
\text { age who were fed any breast milk during the previous day }\end{array}$ \\
\hline Introduction of solid, semisolid or soft foods & $\begin{array}{l}\text { Proportion of infants } 6-8 \text { months (i.e. } \geq 183 \text { to } \leq 274 \mathrm{~d} \text { ) of age } \\
\text { who received solid, semisolid or soft foods during the } \\
\text { previous day }\end{array}$ \\
\hline Minimum dietary diversity & $\begin{array}{l}\text { Proportion of children } 6-23 \text { months (i.e. } \geq 183 \text { to }<730 \mathrm{~d} \text { ) of } \\
\text { age who received foods from four or more food groups } \\
\text { during the previous day }\end{array}$ \\
\hline \multicolumn{2}{|l|}{ Optional indicators } \\
\hline Children who were ever breastfed & $\begin{array}{l}\text { Proportion of children born in the last } 24 \text { months who were } \\
\text { ever breastfed }\end{array}$ \\
\hline Age-appropriate breastfeeding & $\begin{array}{l}\text { Infants } 0-5 \text { months (i.e. }<183 \mathrm{~d} \text { ) of age who received } \\
\text { only breast milk during the previous day, and children } \\
6-23 \text { months (i.e. } \geq 183 \text { to }<730 \mathrm{~d} \text { ) of age who received } \\
\text { breast milk, as well as solid, semisolid or soft foods, during } \\
\text { the previous day divided the number of children } 0-23 \\
\text { months of age }\end{array}$ \\
\hline Predominant breastfeeding under 6 months & $\begin{array}{l}\text { Infants } 0-5 \text { months (i.e. }<183 \mathrm{~d} \text { ) of age who received breast } \\
\text { milk as the predominant source of nourishment during the } \\
\text { previous day }\end{array}$ \\
\hline Continued breastfeeding at 2 years & $\begin{array}{l}\text { Proportion of children } 20-23 \text { months (i.e. } \geq 608 \text { to } \leq 730 \mathrm{~d} \text { ) of } \\
\text { age who were fed breast milk during the previous day }\end{array}$ \\
\hline Bottle feeding & $\begin{array}{l}\text { Proportion of children aged } 0-23 \text { months who drank anything, } \\
\text { including breast milk, from a bottle with a nipple during the } \\
\text { previous day }\end{array}$ \\
\hline
\end{tabular}

*Food groups are: (1) grains, roots and tubers, (2) legumes and nuts, (3) dairy products (milk, yogurt and cheese), (4) flesh foods (meat, fish, poultry and liver/organ meats), (5) eggs, (6) vitamin A-rich fruits and vegetables and (7) other fruits and vegetables.

foods during the last $24 \mathrm{~h}$. Predominant breastfeeding was defined as exclusive breastfeeding but allowing for water, water-based drinks and fruit juice but not non-breast milk, solid/semisolid or soft food. Early introduction of solid/ semisolid or soft foods was defined as having received solid/semisolid or soft foods during the last $24 \mathrm{~h}$ before the age of 6 months. Bottle feeding was defined considering children aged 0-23 months who drank anything, including breast milk, from a bottle with a nipple during the previous day. Continued breastfeeding at 1 and 2 years was defined considering children aged $12-15$ and 20-23 months, respectively, who received breast milk during the day and night before the interview. Minimum dietary diversity was defined among those aged 6-23 months who received foods from four or more food groups (out of seven food groups) during the previous day. These seven food groups are as follows: (1) grains, roots and tubers, (2) legumes and nuts, (3) dairy products (milk, yogurt and cheese), (4) flesh foods (meat, fish, poultry and liver/organ meats), (5) eggs, (6) vitamin A-rich fruits and vegetables and (7) other fruits and vegetables.

Unlike the DHS in other countries, the KNSS does not collect data on socioeconomic status, but data were collected on the type of delivery (normal vaginal or caesarean), place of birth (private or public hospital) and birth weight (BW), as reported by the mothers. The KNSS also collects data on gestational age (as reported by the mother), whether the mother attended antenatal care or received advice on breastfeeding immediately after delivery and, finally, whether the child had any illness that required medical consultation during the last 3 months. The weight of children was measured using a digital scale to the nearest $100 \mathrm{~g}$, while the height of children was measured to the nearest $0 \cdot 1 \mathrm{~cm}$ using a length board. To maintain accuracy, weighing scales were calibrated regularly using a wellknown weight set. Data collectors were trained annually to measure the weight and height of children in a standardised manner.

Data were collected by face-to-face interviews with mothers or child guardians who came to vaccinate their children using a simplified data collection form that was developed in the Arabic language based on WHO IYCF indicators $^{(18)}$. The questionnaire was pilot-tested on 300 participants who were not included in the data analyses. The collected data from pilot testing were used to improve the clarity of questions and further train data collectors to reinforce data collection guidelines prepared for the KNSS. Although the KNSS is a public health survey, all data collection procedures have been reviewed by the Ethics Committee at the Ministry of Health and were granted 
ethical approval (No. 98). Each participant in the KNSS signed a written informed consent form before data collection was initiated.

\section{Statistical methods}

Data were analysed using Stata 12 (StataCorp 2011, release 12). All calculations were performed as per guidelines for both children 0-5 months (<183d) and children 0-23 months $(<730 \mathrm{~d})^{(18)}$. If the sample size was sufficient, the indicators were further disaggregated into small groups. The exact age of children, in days, was calculated by subtracting the date of birth from the date of interview. BMI was calculated as weight $(\mathrm{kg}) /$ height $(\mathrm{m})^{2}$. To assess overweight/obesity, BMI-for-age $z$-scores were calculated using the WHO growth charts, and overweight was defined as $\geq+2$ SD and $<+3 \mathrm{SD}$, while obesity was defined as $\geq+3 \mathrm{SD}^{(23)}$. Whether to use BMI-for-age or weight-forlength (WFL) to define overweight among infants and young children is still debated ${ }^{(24-26)}$. Therefore, we calculated WFL $z$-scores, and overweight was defined as $>+2$ SD, while wasting was defined as $<-2$ SD. Lengthfor-age $z$-scores (LAZ) were calculated, and stunting was defined as $<-2$ SD. Similarly, weight-for-age $z$-scores were calculated, and underweight was defined as $<-2$ SD. The $95 \%$ CIs were calculated for the key indicators using exact binomial distribution. The Mann-Whitney test was used to test the differences in $z$-scores. Logistic regression was used to calculate crude ORs and adjusted ORs (AORs) for the associations between WHO IYCF indicators and stunting (defined as length-for-age <-2 SD) or overweight. Two separate analyses were conducted, first while overweight was defined as BMI-for-age $\geq+2$ SD (Table 6), and second while overweight was defined as weight-for-length $>+2$ SD (Table 7). In the multivariable model, we adjusted for sex, BW, age and illness during the last 3 months. Statistical significance was tested using the chi-square test in univariable models, and the Wald test in multivariable models; factors with $P<0.05$ were deemed statistically significant.

\section{Results}

\section{Description of the study group}

Over the 3-year study period, data were collected on 5839 Kuwaiti children (0-23 months), of whom $50 \cdot 2 \%$ were males. The mother was the source of information on the child in $87.6 \%$ of interviews. The characteristics of the study group are shown in Table 2 . The majority of Kuwaiti mothers had been to antenatal care clinics either in the private sector alone $(57.2 \%)$, the public sector alone (13.5\%) or both $(28.6 \%)$, and only $0.8 \%$ had not been to antenatal care when pregnant with the index child. The majority of Kuwaiti children (79.9\%) were born in private hospitals, while $18.4 \%$ were born in public hospitals. Approximately
Table 2 Characteristics of 5839 children (0-23 months) recruited in the Kuwait Nutritional Surveillance System, 2015-2017

\begin{tabular}{|c|c|c|}
\hline Characteristics & $n$ & $\%$ \\
\hline \multicolumn{3}{|l|}{ Source of information } \\
\hline Mother & 5118 & $87 \cdot 6$ \\
\hline Father & 421 & $7 \cdot 2$ \\
\hline Other guardian & 300 & $5 \cdot 1$ \\
\hline \multicolumn{3}{|l|}{ Sex of the child } \\
\hline Male & 2931 & $50 \cdot 2$ \\
\hline \multicolumn{3}{|l|}{ Age of the child } \\
\hline$<91 \mathrm{~d}$ & 1014 & $17 \cdot 4$ \\
\hline$\geq 91$ to $<183 d$ & 1430 & 24.5 \\
\hline$\geq 183$ to $<730 \mathrm{~d}$ & 3395 & $58 \cdot 1$ \\
\hline \multicolumn{3}{|c|}{$\begin{array}{l}\text { Whether mother visited public health facility during } \\
\text { pregnancy* }\end{array}$} \\
\hline Yes & 2146 & $42 \cdot 0$ \\
\hline No & 2958 & $58 \cdot 0$ \\
\hline \multicolumn{3}{|c|}{$\begin{array}{l}\text { Whether mother visited private health facility during } \\
\text { pregnancy } \dagger\end{array}$} \\
\hline Yes & 4376 & $85 \cdot 8$ \\
\hline No & 727 & $14 \cdot 2$ \\
\hline \multicolumn{3}{|l|}{ Place of birth } \\
\hline Private hospital & 4665 & $79 \cdot 9$ \\
\hline Public hospital & 1073 & $18 \cdot 4$ \\
\hline Others $\ddagger$ & 98 & 1.7 \\
\hline \multicolumn{3}{|l|}{ Type of delivery§ } \\
\hline Vaginal & 4015 & $68 \cdot 8$ \\
\hline Caesarean & 1818 & $31 \cdot 2$ \\
\hline \multicolumn{3}{|l|}{ Birth weight $\|(g)$} \\
\hline Mean & \multicolumn{2}{|c|}{$\begin{array}{r}2940 \cdot 0 \\
584.5\end{array}$} \\
\hline SD & & \\
\hline Very low birth weight, $<1500 \mathrm{~g}$ & 100 & 1.8 \\
\hline Low birth weight, $\geq 1500$ to $<2500 \mathrm{~g}$ & 1131 & $20 \cdot 4$ \\
\hline Normal birth weight, $\geq 2500$ to $<4000 \mathrm{~g}$ & 4212 & $76 \cdot 1$ \\
\hline High birth weight, $\geq 4000 \mathrm{~g}$ & 91 & $1 \cdot 6$ \\
\hline \multicolumn{3}{|c|}{$\begin{array}{l}\text { Any illness during the last } 3 \text { months among children aged } \\
0-23 \text { months }\end{array}$} \\
\hline Yes & 2820 & $48 \cdot 4$ \\
\hline
\end{tabular}

*The question was asked only if the mother was the source of information ( $n 5118$ ), and an answer was missing for fourteen mothers.

$\dagger$ Same remark as the previous question, and an answer was missing for fifteen mothers.

¥Others included those who had their deliveries abroad; there were also three missing values.

$\S A n$ answer was missing for six mothers.

$\|$ As reported by mothers or guardians; 305 could not remember the birth weight of their children.

one-third were born by caesarean section (CS), which was significantly more common in public hospitals compared to private hospitals ( $42.5 v .28 .5 \% ; P<0.001)$. We did not collect data on the clinical indications for CS to elucidate the underlying reasons for this difference between private and public hospitals. The majority of mothers or guardians (94.8\%) reported a recalled BW of their children; the mean (SD) value of BW was $2939.97(584.51) \mathrm{g}$. More than $22.0 \%$ of the children had a low BW $(<2500 \mathrm{~g})$, and $1.6 \%$ had a high BW ( $\geq 4000 \mathrm{~g})$.

\section{Infant and young child feeding practices}

The core and optional indicators for feeding infants and young Kuwaiti children over the 3-year period are shown in Table 3. Only 39.1\% of mothers initiated breastfeeding within the first hour of birth or recovery from a CS. This was 
Table 3 Infant and young child feeding practices for 5839 children (0-23 months) recruited in the Kuwait Nutritional Surveillance System, 2015-2017

\begin{tabular}{|c|c|c|}
\hline Characteristics & $n$ & $\%$ \\
\hline \multicolumn{3}{|c|}{$\begin{array}{l}\text { Whether mother received an advice to breastfeed } \\
\text { her child in hospital* }(N 5032)\end{array}$} \\
\hline Yes & 4361 & $86 \cdot 6$ \\
\hline No & 550 & $10 \cdot 9$ \\
\hline Do not remember & 121 & \\
\hline \multicolumn{3}{|l|}{ Early initiation of breastfeeding $(N 4935)$} \\
\hline Immediately after birth or CS & 1929 & 39 \\
\hline After $1 \mathrm{~h}$ of birth or CS but within $24 \mathrm{~h}$ & 1301 & $26 \cdot 4$ \\
\hline After $\geq 1 \mathrm{~d}$ & 1362 & $27 \cdot 6$ \\
\hline I never initiated breastfeeding & 343 & \\
\hline \multicolumn{3}{|l|}{ Children who were ever breastfed ( $N 5836)$} \\
\hline Yes & 5248 & 89. \\
\hline \multicolumn{3}{|c|}{ Any current breastfeeding (yesterday) (row \%) } \\
\hline $0-3$ months, $N$ 1014; yes & 342 & $33 \cdot 7$ \\
\hline 0-5 months, N 2507; yes & 675 & $26 \cdot 9$ \\
\hline \multicolumn{3}{|l|}{ Exclusive breastfeeding (row \%) } \\
\hline 0-3 months, N 1014; yes & 96 & 9. \\
\hline $0-5$ months, $N 2507$; yes & 200 & $8 \cdot$ \\
\hline \multicolumn{3}{|l|}{ Predominant breastfeeding (row \%) } \\
\hline 0-3 months, $N$ 1014; yes & 123 & 12. \\
\hline $0-5$ months, $N 2507$; yes & 259 & 10 \\
\hline \multicolumn{3}{|l|}{ Age-appropriate breastfeeding (N 5839) } \\
\hline Yes & 429 & 7. \\
\hline \multicolumn{3}{|l|}{ Continued breastfeeding at 1 year $(N 847)$} \\
\hline Yes & 91 & 10. \\
\hline \multicolumn{3}{|l|}{ Continued breastfeeding at 2 years ( $N 186)$} \\
\hline Yes & 16 & $8 \cdot 6$ \\
\hline \multicolumn{3}{|l|}{$\begin{array}{l}\text { Introduction of solid, semisolid or soft foods } \\
(N 1273)\end{array}$} \\
\hline Yes & 878 & $69 \cdot c$ \\
\hline \multicolumn{3}{|l|}{ Minimum dietary diversity (N 3332) } \\
\hline Yes & 1386 & 41.6 \\
\hline \multicolumn{3}{|c|}{ Bottle feeding in children $0-23$ months (N 5836) } \\
\hline Yes & 4176 & $71 \cdot 6$ \\
\hline
\end{tabular}

CS, caesarean section.

*The question was asked only if the mother was the source of information ( $n 5118$ ), and we also excluded women who delivered outside the country; an answer was missing for nine mothers.

†The same remark as the previous question; missing for 106 mothers.

significantly lower among mothers who delivered by CS compared to those who delivered by normal delivery (29.6 v. 43.8\%, respectively; $P<0.001$ ). The majority of Kuwaiti children (0-23 months) were ever breastfed (89.9\%); this indicator showed a significant variation among different governorates $(P<0.001)$. Exclusive breastfeeding (as defined by the WHO) was $9.5 \%$ (95\% CI 7.7, 11.4\%) among infants in the $0-3$ months age group, and $8.0 \%$ (95\% CI 7.0, 9.1\%) among infants in the $0-5$ months age group. Our findings showed that during the day and night before the interview, $84.2 \%$ of infants aged $0-5$ months were fed formula milk. As a result, both predominant breastfeeding and age-appropriate breastfeeding were low: $10.3 \%$ (95\% CI 9.2, 11.6) and $7 \cdot 4 \%$ (95\% CI 6.7, 8.9), respectively.

The introduction of solid/semisolid or soft foods was $69.0 \%(95 \%$ CI 66.3, 71.5$)$ in infants aged $6-8$ months. The early introduction of solid/semisolid or soft foods among infants aged $0-5$ months was low $(6 \cdot 3 \%)$. The proportion of children 6-23 months who received complementary feeding from at least four of the food groups listed by the WHO (minimum dietary diversity) was $41.6 \%$ (95\% CI 39.9, 43.3), while the consumption of eggs and flesh foods in this age group was $22 \cdot 1$ and $41.0 \%$, respectively.

\section{Associations between infant and young child feeding practices and stunting}

The prevalence of stunting, wasting, underweight, overweight and obesity among children 0-23 months is displayed in Table 4 . The prevalence of stunting was $7.5 \%$, while that of wasting was $2 \cdot 4 \%$. Using BMI-for-age, the prevalence of overweight was $6.5 \%$, while that of obesity was $1.6 \%$. The prevalence of overweight was $8.7 \%$ using WFL, which is very similar to the prevalence estimated by BMI-for-age. The prevalence of underweight (weight-forage) was $4.3 \%$, while that of concurrent stunting and overweight/obesity was $0.9 \%$. The associations between IYCF indicators and stunting are shown in Table 5. Although LAZ was significantly lower in the children of mothers who did not initiate early breastfeeding, the odds of stunting was not significantly different between the children of mothers who initiated breastfeeding early and those of mothers who did not (Table 5). Exclusive breastfeeding was significantly associated with stunting in the multivariable analysis, with children who were exclusively breastfed having higher odds of stunted growth (AOR 1.71; $95 \%$ CI 1.08, 2.70; $P=0 \cdot 021$ ). Breastfeeding indicators were calculated based on whether the child was breastfed yesterday; hence they targeted infants and children at different age groups. Therefore, probably the most important indicator in this analysis is age-appropriate breastfeeding because it includes all children aged 0-23 months. Age-appropriate breastfeeding was more common in children with stunting in multivariable analysis (AOR 1.44; $95 \%$ CI 1.01, 2.06; $P=0.046$ ). On the other hand, the introduction of solid/ semisolid or soft foods was inversely associated with stunting in univariable and multivariable analyses (OR 0.57; $95 \%$ CI 0.34, 0.97; $P=0.037$ and AOR 0.52; $95 \%$ CI 0.30, $0.90 ; P=0.021)$. Similarly, there was a borderline significant negative association between achieving the minimum dietary diversity and stunting in the univariable analysis (OR $0.71 ; 95 \%$ CI $0.50,1.00 ; P=0.053$ ), but this was non-significant in the multivariable analysis (AOR 0.74; $95 \%$ CI $0.52,1 \cdot 07 ; P=0 \cdot 108)$.

\section{Associations between infant and young child feeding practices and overweight}

The associations between IYCF indicators and overweight (based on BMI-for-age; the term overweight includes obesity) are depicted in Table 6. Of all IYCF indicators, only age-appropriate breastfeeding was inversely associated with overweight in the univariable and multivariable analyses (OR 0.57; $95 \%$ CI 0.36, 0.89; $P=0.013$ and AOR $0 \cdot 62 ; 95 \%$ CI $0.39,0.98 ; P=0.043)$. The odds of overweight were significantly lower in children who were breastfed 
Table 4 Prevalence of stunting, wasting, underweight, overweight and obesity among 5839 children (0-23 months) recruited in the Kuwait Nutritional Surveillance System, 2015-2017

\begin{tabular}{|c|c|c|c|c|c|c|c|c|c|c|c|}
\hline \multirow{2}{*}{$\begin{array}{l}\text { Age group } \\
\text { (0-23 months) }\end{array}$} & \multirow[b]{2}{*}{ Sample $^{*}(N)$} & \multicolumn{2}{|c|}{ Stuntingt } & \multicolumn{2}{|c|}{ Wasting $\ddagger$} & \multicolumn{2}{|c|}{ Underweight§ } & \multicolumn{2}{|c|}{ Overweight $\|$} & \multicolumn{2}{|c|}{ Obesity } \\
\hline & & $n$ & $\%$ & $n$ & $\%$ & $n$ & $\%$ & $n$ & $\%$ & $n$ & $\%$ \\
\hline Total & 5839 & 431 & 7.5 & 141 & $2 \cdot 4$ & 252 & 4.3 & 379 & 6.5 & 91 & 1.6 \\
\hline Male & 2931 & 237 & 8.2 & 78 & $2 \cdot 7$ & 151 & $5 \cdot 2$ & 205 & 7.0 & 45 & 1.6 \\
\hline Female & 2908 & 194 & $6 \cdot 8$ & 63 & $2 \cdot 2$ & 101 & 3.5 & 174 & 6.0 & 46 & 1.6 \\
\hline
\end{tabular}

*Numbers may vary due to excluding children with biologically implausible $z$-scores (ninety-five children with length-for-age $z$-score either $<-6$ or $>6$; forty-eight children with weight-for-length $z$-score either $<-5$ or $>5$; thirty children with weight-for-age $z$-score either $<-6$ or $>5$; and forty-five children with BMI-for-age $z$-score either $<-5$ or $>5$ ). †Stunting: length-for-age $<-2$ SD.

$\ddagger$ Wasting: weight-for-length $<-2 \mathrm{SD}$.

§Underweight: weight-for-age $<-2$ SD.

॥Overweight: BMI-for-age $>+2$ SD to $<+3$ SD.

ๆObesity: BMI-for-age >+3 SD.

Table 5 Associations between infant and young child feeding indicators and stunting, Kuwait Nutritional Surveillance System, 2015-2017

\begin{tabular}{|c|c|c|c|c|c|c|c|c|c|}
\hline \multirow{2}{*}{$\begin{array}{l}\text { Infant and young child feeding } \\
\text { indicator }\end{array}$} & \multirow[b]{2}{*}{$N$} & \multicolumn{2}{|r|}{ LAZ } & \multicolumn{2}{|c|}{$\begin{array}{c}\text { Stunting } \\
\text { (prevalence) }\end{array}$} & \multirow[b]{2}{*}{ Crude OR } & \multirow[b]{2}{*}{$95 \% \mathrm{Cl}$} & \multirow[b]{2}{*}{ Adjusted $^{\star}$ OR } & \multirow[b]{2}{*}{$95 \% \mathrm{Cl}$} \\
\hline & & Median & IQR & $n$ & $\%$ & & & & \\
\hline \multicolumn{10}{|l|}{ Early initiation of BF } \\
\hline No & 2953 & -0.17 & $-1.02,0.57$ & 247 & $8 \cdot 36$ & 1 & Reference & 1 & Reference \\
\hline $\begin{array}{l}\text { Yes } \\
P\end{array}$ & 1893 & $\begin{array}{l}-0.15 \\
0.011\end{array}$ & $-0.88,0.68$ & 127 & $6 \cdot 71$ & $\begin{array}{l}0.79 \\
0.179\end{array}$ & $0.63,0.98$ & $\begin{array}{l}0.92 \\
0.494\end{array}$ & $0.73,1.16$ \\
\hline \multicolumn{10}{|l|}{ Exclusive BF } \\
\hline No & 2267 & -0.44 & $-1.26,0.32$ & 258 & 11.38 & 1 & Reference & 1 & Reference \\
\hline $\begin{array}{l}\text { Yes } \\
P\end{array}$ & 199 & $\begin{array}{c}-0.54 \\
0.131\end{array}$ & $-1 \cdot 6,0 \cdot 18$ & 29 & 14.57 & $\begin{array}{l}1.33 \\
0.179\end{array}$ & $0.88,2 \cdot 01$ & $\begin{array}{l}1 \cdot 71 \\
0.021\end{array}$ & $1.08,2 \cdot 70$ \\
\hline \multicolumn{10}{|l|}{ Age-appropriate BF } \\
\hline No & 5319 & -0.13 & $-0.94,0.64$ & 390 & $7 \cdot 33$ & 1 & Reference & 1 & Reference \\
\hline $\begin{array}{l}\text { Yes } \\
P\end{array}$ & 425 & $\begin{array}{l}-0.33 \\
<0.001\end{array}$ & $-1.22,0.44$ & 41 & $9 \cdot 65$ & $\begin{array}{l}1.35 \\
0.082\end{array}$ & $0.96,1.89$ & $\begin{array}{l}1.44 \\
0.046\end{array}$ & $1.01,2.06$ \\
\hline \multicolumn{10}{|l|}{ Continued BF at 1 year } \\
\hline No & 858 & 0.22 & $-0.51,1.02$ & 32 & 3.73 & 1 & Reference & 1 & Reference \\
\hline $\begin{array}{l}\text { Yes } \\
P\end{array}$ & 80 & $\begin{array}{r}-0.17 \\
0.003\end{array}$ & $-0.81,0.60$ & 5 & $6 \cdot 25$ & $\begin{array}{l}1 \cdot 72 \\
0.268\end{array}$ & $0.65,4.55$ & $\begin{array}{l}1.71 \\
0.333\end{array}$ & $0.58,5.08$ \\
\hline \multicolumn{10}{|c|}{ Introduction of solid, semisolid or soft foods } \\
\hline No & 392 & 0.03 & $-0.90,0.74$ & 26 & $6 \cdot 63$ & 1 & Reference & 1 & Reference \\
\hline $\begin{array}{l}\text { Yes } \\
P\end{array}$ & 865 & $\begin{array}{r}-0.03 \\
0.99\end{array}$ & $-0.80,0.68$ & 34 & $3 \cdot 93$ & $\begin{array}{l}0.57 \\
0.037\end{array}$ & $0.34,0.97$ & $\begin{array}{l}0.52 \\
0.021\end{array}$ & $0.30,0.90$ \\
\hline \multicolumn{10}{|l|}{ Minimum dietary diversity } \\
\hline No $(<4$ groups $)$ & 1906 & 0.02 & $-0.80,0.77$ & 95 & 4.98 & 1 & Reference & 1 & Reference \\
\hline $\begin{array}{l}\text { Yes ( } \geq 4 \text { groups }) \\
P\end{array}$ & 1372 & $\begin{array}{c}0.11 \\
<0.001\end{array}$ & $-0.57,-0.89$ & 49 & 3.57 & $\begin{array}{l}0.71 \\
0.053\end{array}$ & $0.50,1.00$ & $\begin{array}{l}0.74 \\
0.108\end{array}$ & $0.52,1.07$ \\
\hline
\end{tabular}

BF, breastfeeding; IQR, interquartile range (Q1, Q3); LAZ, length-for-age $z$-score. ${ }^{\star}$ Adjusted for sex, age, birth weight and illness during the last 3 months.

according to this indicator compared to children who were not. Early introduction of solid/semisolid or soft foods before the age of 6 months was positively associated with overweight (OR 2.24; $95 \%$ CI 1.27, 3.96; $P=0.005$ and AOR $2 \cdot 36 ; 95 \%$ CI 1.83, 6.18; $P<0.001)$. We repeated the above analysis while defining overweight based on WFL and present the results in Table 7. Similar to the previous analysis, age-appropriate breastfeeding was inversely associated with overweight in univariable and multivariable analyses (OR 0.55; $95 \%$ CI 0.36, 0.86; $P=0.008$ and AOR 0.58; $95 \%$ CI $0.37,0.92 ; P=0.021$ ). In this analysis (Table 7), continued breastfeeding at 1 year was also inversly associated with overweight, with the odds of overweight being significantly lower among those who were breastfed at
1 year (OR 0.27; $95 \%$ CI $0.08,1.88 ; P=0.030$ and AOR 0.29 ; $95 \%$ CI $0.09,0.94 ; P=0.040$ ). Finally, none of the IYCF indicators showed a significant association with wasting. Continued breastfeeding at 1 year was more common among children who were underweight (AOR 5.36; $95 \%$ CI $2 \cdot 65,10.86 ; P<0.001)$, while achieving minimum dietary diversity was inversely associated with underweight (AOR 0.26; $95 \%$ CI 0.16, 0.45; $P<0 \cdot 001$ ) (data not shown).

\section{Discussion}

This study aimed to assess IYCF practices in Kuwait as per the WHO indicators and to investigate the associations 
Table 6 Association between infant and young child feeding indicators and overweight (including obesity based on BMI-for-age): data from the Kuwait Nutritional Surveillance System, 2015-2017

\begin{tabular}{|c|c|c|c|c|c|c|c|c|c|}
\hline \multirow{2}{*}{$\begin{array}{l}\text { Infant and young child feeding } \\
\text { indicators }\end{array}$} & \multirow[b]{2}{*}{$N$} & \multicolumn{2}{|c|}{ BMI z-score } & \multicolumn{2}{|c|}{$\begin{array}{l}\text { Overweight } \\
\text { (prevalence) }\end{array}$} & \multirow[b]{2}{*}{ Crude OR } & \multirow[b]{2}{*}{$95 \% \mathrm{Cl}$} & \multirow[b]{2}{*}{ Adjusted* OR } & \multirow[b]{2}{*}{$95 \% \mathrm{Cl}$} \\
\hline & & Median & IQR & $n$ & $\%$ & & & & \\
\hline \multicolumn{10}{|l|}{ Early initiation of BF } \\
\hline No & 2983 & 0.39 & $-0.40,1.13$ & 239 & 8.01 & 1 & Reference & 1 & Reference \\
\hline $\begin{array}{l}\text { Yes } \\
P\end{array}$ & 1914 & $\begin{array}{l}0.29 \\
0.086\end{array}$ & $-0.41,1.08$ & 141 & $7 \cdot 37$ & $\begin{array}{l}0.91 \\
0.410\end{array}$ & $0.74,1.13$ & $\begin{array}{l}0.92 \\
0.449\end{array}$ & $0.73,1.15$ \\
\hline \multicolumn{10}{|l|}{ Exclusive BF } \\
\hline No & 2286 & 0.12 & $-0.56,0.85$ & 112 & 4.90 & 1 & Reference & 1 & Reference \\
\hline $\begin{array}{l}\text { Yes } \\
P\end{array}$ & 199 & $\begin{array}{l}0.08 \\
0.330\end{array}$ & $-0.72,0.69$ & 10 & 5.03 & $\begin{array}{l}1.03 \\
0.937\end{array}$ & $0.53,1.99$ & $\begin{array}{l}0.90 \\
0.783\end{array}$ & $0.45,1.83$ \\
\hline \multicolumn{10}{|l|}{ Age-appropriate BF } \\
\hline No & 5370 & 0.38 & $-0.37,1 \cdot 16$ & 449 & $8 \cdot 36$ & 1 & Reference & 1 & Reference \\
\hline $\begin{array}{l}\text { Yes } \\
P\end{array}$ & 424 & $\begin{array}{c}0.08 \\
<0.001\end{array}$ & $-0.59,0.80$ & 21 & 4.95 & $\begin{array}{l}0.57 \\
0.013\end{array}$ & $0.36,0.89$ & $\begin{array}{l}0.62 \\
0.043\end{array}$ & $0.39,0.98$ \\
\hline \multicolumn{10}{|l|}{ Continued BF at 1 year } \\
\hline No & 875 & 0.75 & $-0.04,1.48$ & 102 & 11.66 & 1 & Reference & 1 & Reference \\
\hline $\begin{array}{l}\text { Yes } \\
P\end{array}$ & 90 & $\begin{array}{l}0.30 \\
0.012\end{array}$ & $-0.37,1 \cdot 30$ & 6 & $6 \cdot 67$ & $\begin{array}{l}0.54 \\
0.153\end{array}$ & $0.23,1 \cdot 27$ & $\begin{array}{l}0.57 \\
0.204\end{array}$ & $0.24,1.35$ \\
\hline \multicolumn{10}{|c|}{ Introduction of solid, semisolid or soft foods } \\
\hline No & 393 & 0.30 & $-0.45,0.97$ & 28 & $7 \cdot 12$ & 1 & Reference & 1 & Reference \\
\hline $\begin{array}{l}\text { Yes } \\
P\end{array}$ & 871 & $\begin{array}{l}0.40 \\
0.184\end{array}$ & $-0.41,1 \cdot 11$ & 70 & 8.04 & $\begin{array}{l}1.14 \\
0.575\end{array}$ & $0.72,1.80$ & $\begin{array}{l}1.10 \\
0.692\end{array}$ & $0.68,1.77$ \\
\hline \multicolumn{10}{|l|}{ Minimum dietary diversity } \\
\hline No (<4 groups) & 1933 & 0.53 & $-0.27,1 \cdot 26$ & 197 & $10 \cdot 19$ & 1 & Reference & 1 & Reference \\
\hline $\begin{array}{l}\text { Yes ( } \geq 4 \text { groups }) \\
P\end{array}$ & 1376 & $\begin{array}{l}0.64 \\
0.002\end{array}$ & $-0.11,1.42$ & 151 & $10 \cdot 97$ & $\begin{array}{l}1.09 \\
0.470\end{array}$ & $0.87,1.36$ & $\begin{array}{l}0.79 \\
0.094\end{array}$ & $0.60,1.04$ \\
\hline
\end{tabular}

$B F$, breastfeeding; IQR, interquartile range (Q1, Q3).

${ }^{*}$ Adjusted for sex, age, birth weight and illness during the last 3 months.

Table 7 Associations between infant and young child feeding indicators and overweight (based on weight-for-length): data from the Kuwait Nutritional Surveillance System, 2015-2017

\begin{tabular}{|c|c|c|c|c|c|c|c|c|c|}
\hline \multirow{2}{*}{$\begin{array}{l}\text { Infant and young } \\
\text { child feeding } \\
\text { indicators }\end{array}$} & \multirow[b]{2}{*}{$N$} & \multicolumn{2}{|c|}{ WFL z-score } & \multicolumn{2}{|c|}{$\begin{array}{l}\text { Overweight } \\
\text { (prevalence) }\end{array}$} & \multirow[b]{2}{*}{ Crude OR } & \multirow[b]{2}{*}{$95 \% \mathrm{Cl}$} & \multirow[b]{2}{*}{ Adjusted* OR } & \multirow[b]{2}{*}{$95 \% \mathrm{Cl}$} \\
\hline & & Median & IQR & $n$ & $\%$ & & & & \\
\hline \multicolumn{10}{|l|}{ Early initiation of BF } \\
\hline No & 2982 & 0.53 & $-0.26,1.26$ & 239 & $8 \cdot 7$ & 1 & Reference & 1 & Reference \\
\hline $\begin{array}{l}\text { Yes } \\
P\end{array}$ & 1912 & $\begin{array}{l}0.42 \\
0.02\end{array}$ & $-0.30,1 \cdot 21$ & 152 & $7 \cdot 9$ & $\begin{array}{l}0.91 \\
0.365\end{array}$ & $0 \cdot 74,1 \cdot 11$ & $\begin{array}{l}0.92 \\
0.457\end{array}$ & $0.74,1.14$ \\
\hline \multicolumn{10}{|l|}{ Exclusive BF } \\
\hline No & 2281 & 0.37 & $-0 \cdot 38,1 \cdot 12$ & 161 & $7 \cdot 1$ & 1 & Reference & 1 & Reference \\
\hline $\begin{array}{l}\text { Yes } \\
P\end{array}$ & 199 & $\begin{array}{l}0.37 \\
0.803\end{array}$ & $-0.38,1.12$ & 12 & $6 \cdot 0$ & $\begin{array}{l}0.84 \\
0.585\end{array}$ & $0.46,1.55$ & $\begin{array}{l}0.80 \\
0.504\end{array}$ & $0.42,1.52$ \\
\hline \multicolumn{10}{|l|}{ Age-appropriate BF } \\
\hline No & 5366 & 0.52 & $-0.23,1.27$ & 483 & $9 \cdot 0$ & 1 & Reference & 1 & Reference \\
\hline $\begin{array}{l}\text { Yes } \\
P\end{array}$ & 425 & $\begin{array}{c}0.21 \\
<0.001\end{array}$ & $-0.44,1.03$ & 22 & $5 \cdot 2$ & $\begin{array}{l}0.55 \\
0.008\end{array}$ & $0.36,0.86$ & $\begin{array}{l}0.58 \\
0.021\end{array}$ & $0.37,0.92$ \\
\hline \multicolumn{10}{|c|}{ Continued BF at 1 year } \\
\hline No & 874 & 0.76 & $0.04,1.46$ & 98 & $11 \cdot 2$ & 1 & Reference & 1 & Reference \\
\hline $\begin{array}{l}\text { Yes } \\
P\end{array}$ & 90 & $\begin{array}{l}0.34 \\
0.004\end{array}$ & $-0.41,1.33$ & 3 & $3 \cdot 3$ & $\begin{array}{l}0.27 \\
0.030\end{array}$ & $0.08,1.88$ & $\begin{array}{l}0.29 \\
0.040\end{array}$ & $0.09,0.94$ \\
\hline \multicolumn{10}{|c|}{ Introduction of solid, semi-solid or soft foods } \\
\hline No & 393 & 0.40 & $-0.33,1 \cdot 12$ & 32 & $8 \cdot 1$ & 1 & Reference & 1 & Reference \\
\hline $\begin{array}{l}\text { Yes } \\
P\end{array}$ & 873 & $\begin{array}{l}0.51 \\
0.262\end{array}$ & $-0 \cdot 30,1 \cdot 18$ & 70 & $8 \cdot 0$ & $\begin{array}{l}0.98 \\
0.940\end{array}$ & $0.64,1.52$ & $\begin{array}{l}0.94 \\
0.777\end{array}$ & $0.59,1.47$ \\
\hline \multicolumn{10}{|c|}{ Minimum dietary diversity } \\
\hline No (<4 groups) & 1934 & 0.61 & $-0.21,1.31$ & 187 & $9 \cdot 7$ & 1 & Reference & 1 & Reference \\
\hline $\begin{array}{l}\text { Yes ( } \geq 4 \text { groups) } \\
P\end{array}$ & 1377 & $\begin{array}{l}0.63 \\
0.058\end{array}$ & $-0.09,1.4$ & 145 & 10.5 & $\begin{array}{l}1 \cdot 10 \\
0.416\end{array}$ & $0.87,1.38$ & $\begin{array}{l}0.87 \\
0.320\end{array}$ & $0.66,1.15$ \\
\hline
\end{tabular}

$\mathrm{BF}$, breastfeeding; WFL, weight-for-length; IQR, interquartile range (Q1, Q3).

${ }^{*}$ Adjusted for sex, age, birth weight and illness during the last 3 months. 
between IYCF indicators and anthropometric outcomes. WHO IYCF indicators have been rarely reported from high-income countries ${ }^{(8)}$ such as the oil-rich countries in the Middle East. We used data from the KNSS (20152017), which was reviewed to collect data on IYCF practices as per the WHO approach. Our findings showed that only a minority of Kuwaiti mothers initiated breastfeeding on time, and only a minority exclusively breastfed their infants during the first 6 months of life. Our results also showed that age-appropriate breastfeeding was inversely associated with overweight, while early introduction of solid/semisolid or soft food before the age of 6 months was more common in children who were overweight.

\section{Infant and young child feeding practices}

In our study, approximately 39\% of mothers initiated breastfeeding within 1 hour of birth, which is similar to estimates reported from various low-, middle- ${ }^{(8,27)}$ and high-income countries ${ }^{(28)}$. This estimate is also slightly lower than the world's average for the early initiation of breastfeeding $(42 \%)^{(29)}$. We have demonstrated that more than $31 \%$ of Kuwaiti children were delivered by CS, which is one of the highest rates of CS in high-income countries $^{(30,31)}$. In our study, early initiation of breastfeeding to babies delivered by CS was significantly lower compared to those delivered by normal vaginal delivery. A systematic review of fifty-three studies from thirty-three countries found breastfeeding initiation to be significantly lower after birth by CS compared to birth by normal vaginal delivery ${ }^{(32)}$. The indications for CS, the type of anaesthesia and baby's condition at birth can all contribute to the separation of the mother and the baby, impacting the timing of breastfeeding $^{(33)}$. It has been suggested that a successful breastfeeding after CS may require physical, psychological and emotional support, but only a limited number of interventions to improve breastfeeding among mothers who deliver by CS have been evaluated ${ }^{(30)}$. In a recent literature review, an intervention that included parent education and targeted breastfeeding support was found to increase the initiation and continuation of breastfeeding, but the quality of the studies was not adequate to draw a conclusion ${ }^{(30)}$. In our study, it is worth noting that all breastfeeding indicators, except for the early initiation of breastfeeding, were not significantly different between babies who were born by CS and those who were born by vaginal delivery. The fact that all deliveries occur in hospitals in Kuwait ${ }^{(34)}$ shows the importance of efforts to improve early initiation of breastfeeding at the hospital level through initiatives such as baby-friendly hospitals. It is also worth noting that most of these deliveries occurred in private hospitals; therefore, efforts to improve early initiation of breastfeeding that do not include the private sector are unlikely to be productive. To date, very few hospitals (one public and one private) have been declared baby-friendly in Kuwait, and the impact of this initiative has never been formally evaluated or demonstrated in Kuwait. Mothers who initiated breastfeeding late were asked for the reason in an open question. Their answers were non-specific, such as the mother being tired or there was no breast milk, which reflects mothers' poor knowledge and lack of support at the hospital level to encourage mothers to initiate breastfeeding early after delivery. Qualitative studies are recommended to investigate the underlying reasons for delays in the initiation of breastfeeding both in public and private hospitals.

As per the WHO approach, exclusive breastfeeding was defined so when babies were breastfed on the day or night preceding the interview and received no liquid or complementary foods. Based on this definition, only approximately $8 \%$ of infants aged $0-5$ months were exclusively breastfed. Furthermore, it has been suggested that this definition may overestimate exclusive breastfeeding, as some infants who are given liquids irregularly may not do so on the day before the interview ${ }^{(18,19)}$. In fact, more than $84 \%$ of infants aged $0-5$ months were fed formula milk on the day and night preceding the interview. Exclusive breastfeeding in our setting seemed to be substantially lower than in various low- ${ }^{(8,27)}$, middle- ${ }^{(8)}$ and high-income countries ${ }^{(28,35)}$. In our setting, exclusive breastfeeding seemed to be undermined by feeding infants formula milk rather than by early introduction of foods or drinks (only $6 \%$ of infants aged $0-5$ months received solid/semisolid or soft foods with or without breast milk). As a result, other breastfeeding indicators, such as age-appropriate breastfeeding and predominant breastfeeding, were also low. Efforts to improve breastfeeding in our setting should focus on reducing the use of formula milk in infants aged $0-5$ months. Unlike low-income countries, the cost of formula milk is not a major financial burden for most Kuwaiti families ${ }^{(36)}$, and it is unfortunate that formula milk is partially subsidised by the government. While the availability of subsidised infant formula milk through welfare programmes in the United Kingdom and the United States is thought to be an economic factor that may have contributed unintentionally to low breastfeeding practices among women in lowincome groups ${ }^{(37)}$, it is not clear if this has an impact on breastfeeding in Kuwait. There are concerns about the quality and generalisability of the evidence demonstrating the effectiveness of interventions that presumably improve the indicators of breastfeeding ${ }^{(38)}$. This highlights the need to locally test interventions that aim to overcome barriers to breastfeeding in Kuwait and other oil-rich countries in the Gulf region.

Although the recommendation that infants should be exclusively breastfed until the age of 6 months is widely acceptable, the age at which complementary food should be introduced (3-4 v. 6 months) remains under some debate ${ }^{(39,40)}$. It has been suggested that this recommendation should be applied to the population level rather than to individuals, and that mothers who are unwilling or unable to breastfeed should be supported ${ }^{(39-41)}$. Approximately $69 \%$ of infants aged $6-8$ months were fed solid/semisolid 
or soft foods during the day and night preceding the interview in our setting, which is similar to that reported from most countries, including the MENA region, but lower than that reported from Latin America and the Caribbean region $^{(42)}$. This also means that a considerable number of children aged 6-8 months did not receive solid/semisolid or soft foods on the day and night before the interview. As mentioned above, introducing solid/semisolid or soft foods before the recommended age was not common in our setting as only less than $10 \%$ consumed solid/semisolid or soft foods at the age of 4-5 months (91-183d). In some settings, half of the infants aged $4-5$ months were reported to be already consuming solid/semisolid or soft foods ${ }^{(42,43)}$.

More than $40 \%$ of children aged 6-23 months achieved a minimum dietary diversity, which is higher than that reported from low-income countries ${ }^{(27)}$, or global estimates except for Latin America and the Caribbean region ${ }^{(42)}$. However, a minimum dietary diversity was achieved only in less than $15 \%$ of infants aged 6-11 months, which is the period facing the greatest challenge to meet nutritional requirements ${ }^{(14,39)}$. Unlike low-income settings, Kuwait is an affluent country, and foods are subsidised for Kuwaiti families; thus, it is likely that cultural beliefs and poor knowledge of what constitutes an adequate diet for young children are the underlying reasons. Previously, it was demonstrated that diet diversity among infants and young children is poor even among rich families ${ }^{(42)}$. The indicators of complementary feeding in Kuwait seem to be good compared with high-income countries, which is consistent with the previous observation that in countries where continued breastfeeding at 1 and 2 years is low, the indicators of complementary feeding are usually high ${ }^{(42)}$

\section{Associations between infant and young child feeding practices and stunting}

It has been suggested that the importance of WHO IYCF indicators should be judged on their ability to predict anthropometric outcomes. This is because they are not meant to be merely used to monitor IYCF practices, but also to identify populations at risk and to evaluate the impact of nutritional interventions ${ }^{(27)}$. We explored the associations between WHO IYCF indicators and anthropometric outcomes, including stunting, underweight and overweight. Our data suggest that breastfeeding indicators are more common in children aged $0-23$ months with stunting. In particular, we found that age-appropriate breastfeeding and exclusive breastfeeding were significantly associated with stunting. Children who were appropriately breastfed according to their age had higher odds of stunted growth compared to those who were not. Similar to our findings, Jones et al. ${ }^{(27)}$ examined the associations between IYCF indicators and stunting in various low-income countries and reported a negative association between exclusive breastfeeding and LAZ, which was significant in two countries. In our study, there was no significant difference in
LAZ between babies who were exclusively breastfed and those who were not $(P=0 \cdot 131)$, but LAZ was significantly lower among children who were appropriately breastfed according to their age $(P<0.001)$. Introducing solid/semisolid or soft foods was inversely associated with stunting, which is similar to that reported in other studies $^{(27)}$. Additionally, achieving a minimum dietary diversity was inversely associated with stunting (with borderline significance) in univariable analysis, but lost statistical significance in the multivariable analysis. This is similar to other studies that showed that the consumption of a minimally diverse diet at 6 months of age has been associated with greater LAZ at the age of 18 months ${ }^{(44,45)}$. In our analysis, except for fruits and vegetables, all other complementary foods were inversely associated with stunting, which is consistent with other studies that showed that children 6-23 months of age who consumed no animal-source foods had significantly higher odds of stunting ${ }^{(46)}$.

In a study in Cambodia, using the DHS data, the authors reported that compliance with all of the age-specific WHO IYCF indicators was not associated with stunted growth ${ }^{(47)}$. In another study that aimed to investigate the overall average effect of WHO IYCF indicators in fourteen low-income countries, children who were fed as per the IYCF indicators were significantly less likely to be underweight or stunted $^{(48)}$. These two studies combined breastfeeding and complementary feeding into one indicator, and thus their results cannot be directly compared with our findings. However, our data, in addition to other studies ${ }^{(27)}$, suggest that breastfeeding indicators are either not associated with stunting, or positively associated with stunting (i.e. negatively associated with LAZ). Although this could be a genuine association, it may be explained by the nature of cross-sectional data collection on WHO IYCF indicators, which makes it possible that the mothers of children with poor growth tend to breastfeed their children (reverse causality). On the other hand, the timely introduction of complementary foods and achieving a minimum dietary diversity seemed to be inversely associated with stunting. Growth during the first 2 years of life is also affected by prematurity and $\mathrm{BW}^{(49,50)}$. In our data, $\mathrm{BW}$ was a strong predictor of stunting $(P<0.001)$, overweight $(P=0.018)$ and underweight $(P<0.001)$. Therefore, we recommend that studies looking at the associations between WHO IYCF indicators and anthropometric measurements at an early age adjust for prematurity and BW, or at least for one of these factors if strong collinearity is found between them.

\section{Associations between infant and young child feeding practices and overweight}

Overweight and obesity among children is increasing even in low-income countries. The link between WHO IYCF indicators and stunting or underweight has been described before, but studies investigating the link between 
WHO IYCF indicators and overweight or obesity are lacking. Of all WHO IYCF indicators, only age-appropriate breastfeeding was inversely associated with overweight in univariable and multivariable analyses (Table 6). This is of public health significance in Kuwait, where more than $45 \%$ of school children are either overweight or obese ${ }^{(21)}$. Our findings are consistent with the conclusion from a literature review of 113 studies conducted mostly in high-income countries, in which a longer period of breastfeeding was associated with a reduction in the odds of overweight and obesity ${ }^{(22)}$. Efforts to tackle obesity in Kuwait should focus on early-life exposure, including breastfeeding and other IYCF practices. Some studies have suggested that early introduction of complementary foods (before the age of 4 or 6 months) may increase the risk of having a BMI that is higher than normal ${ }^{(15-17,51)}$, but other studies did not support this assertion ${ }^{(52)}$. In our data, only a small number of children in this age group received solid/ semisolid or soft foods, and this was more common among children who were overweight in univariable and multivariable analyses.

\section{Strengths and limitations}

Our study provides insights into the WHO IYCF practices for a high-income country in the Middle East that are distinct from other neighbouring low-income countries in the region. Unlike previous studies that focused only on underweight, wasting and stunting, we also looked at the associations between WHO IYCF indicators and overweight. However, our data have several limitations, one of which is the cross-sectional data collection approach, which makes the inference about the temporal associations between WHO IYCF indicators and anthropometric measures unclear. It is possible that a mother may have changed the way she feeds her child if she felt his/her growth was unsatisfactory. The other limitation of this study is the lack of data on the socioeconomic status of participants. Additionally, because different WHO IYCF indicators target different age groups (e.g. exclusive breastfeeding target infants aged 0-5 months), the sample size differed. Also, we did not collect any data from those who refused to participate. We reported data on five core and four optional WHO IYCF indicators. Three core indicators (minimum meal frequency, minimum acceptable diet, and consumption of iron-rich or ironfortified foods) were not covered for operational reasons. Finally, for several logistical reasons, the KNSS collects data only on Kuwaitis; thus, our findings cannot be extrapolated to non-Kuwaitis living in Kuwait. The latter comprises a diverse group of South East Asians, South Asians and Arabs; hence, describing the IYCF practices in this group may require separate studies that take into account the cultural differences.

\section{Conclusion}

We documented the IYCF practices according to the WHO IYCF indicators in Kuwait. We found that only a minority of Kuwaiti mothers initiated breastfeeding immediately after birth, and that less than one out of ten infants aged 0-5 months were exclusively breastfed. More than eight of every ten infants aged $0-5$ months were fed formula milk. Efforts are needed to improve early initiation of breastfeeding in both private and public hospitals, and to discourage the use of infant formula milk. Our findings suggest that age-appropriate breastfeeding is inversely associated with overweight, which is of public health significance in Kuwait, where childhood obesity is a major public health issue. Policymakers should recognise the impact of suboptimal feeding practices on children in terms of child survival, educational potential and chronic non-communicable diseases later in life. Such an understanding will help to scale up interventions to improve IYCF practices in Kuwait based on locally generated evidence. Finally, our data suggest that the associations between different WHO IYCF indicators and stunting, as well as overweight is complex, which reflects the need for a better understanding of WHO IYCF indicators in both low- and high-income settings.

\section{Acknowledgements}

Acknowledgements: We would like to thank Dr Mona Alsumaie for her efforts during the review of KNSS. We also would like to thank Dr Reem Al-Sabah for comments on the first draft of this article. Financial support: KNSS is funded by the Kuwaiti government. This research received no specific grant from any funding agency, commercial or not-for-profit sectors. Conflict of interest: None. Authorship: A.A.-T. supervised data collection, analysed the data and drafted the manuscript. N.A. supervised data collection, contributed to data interpretation and revised the manuscript with significant intellectual input. M.S.H. contributed to data interpretation and revised the manuscript with significant intellectual input. F.A. supervised data collection and data entry, contributed to data management and revised the manuscript with significant intellectual input. N.A.-D. supervised data collection and data entry, contributed to data management and revised the manuscript with significant intellectual input. M.S. supervised data collection and data entry, contributed to data management and revised the manuscript with significant intellectual input. Ethics of human subjectparticipation: This study was conducted according to the guidelines laid down in the Declaration of Helsinki, and all procedures involving research study participants were approved by the Ethics Committee at the Ministry of Health in Kuwait (No. 98). Written informed consent was obtained from all parents or guardians. 


\section{References}

1. Lodge CJ, Tan DJ, Lau MX et al. (2015) Breastfeeding and asthma and allergies: a systematic review and meta-analysis. Acta Paediatr 104, 38-53.

2. Horta B \& Victora C (2013) Short-Term Effects of Breastfeeding: A Systematic Review of the Benefits of Breastfeeding on Diarboea and Pneumonia Mortality. Geneva: World Health Organization.

3. Sankar MJ, Sinha B, Chowdhury R et al. (2015) Optimal breastfeeding practices and infant and child mortality: a systematic review and meta-analysis. Acta Paediatr 104, $3-13$.

4. World Health Organization (2000) Effect of breastfeeding on infant and child mortality due to infectious diseases in less developed countries: a pooled analysis. WHO collaborative study team on the role of breastfeeding on the prevention of infant mortality. Lancet 355, 451-455.

5. Horta B \& Victora CG (2013) Long-Term Effects of Breastfeeding: A Systematic Review. Geneva: World Health Organization.

6. Dewey KG \& Begum K (2011) Long-term consequences of stunting in early life. Matern Child Nutr 7, Suppl. 3, $5-18$.

7. World Health Organization (2001) Complementary Feeding: Report of the Global Consultation, and Summary of Guiding Principles for Complementary Feeding of the Breastfed Child. Geneva: World Health Organization

8. Victora CG, Bahl R, Barros AJ et al. (2016) Breastfeeding in the 21st century: epidemiology, mechanisms, and lifelong effect. Lancet 387, 475-490.

9. Cai X, Wardlaw T \& Brown DW (2012) Global trends in exclusive breastfeeding. Int Breastfeed J 7, 12.

10. O'Dowd A (2017) Global drive to increase breast feeding is unveiled. BMJ 358, j3681.

11. UNICEF (2018) Breastfeeding: A Mother's Gift, for Every Child. https://www.unicef.org/publications/files/UNICEF_ Breastfeeding_A_Mothers_Gift_for_Every_Child.pdf (accessed November 2018).

12. Aguayo VM (2017) Complementary feeding practices for infants and young children in South Asia. A review of evidence for action post-2015. Matern Child Nutr 13, Suppl. 2, doi: $10.1111 / \mathrm{mcn} .12439$.

13. Dewey KG (2016) Reducing stunting by improving maternal, infant and young child nutrition in regions such as South Asia: evidence, challenges and opportunities. Matern Child Nutr 12, Suppl. 1, 27-38.

14. Dewey KG (2013) The challenge of meeting nutrient needs of infants and young children during the period of complementary feeding: an evolutionary perspective. J Nutr $\mathbf{1 4 3}$ 2050-2054.

15. Sun C, Foskey RJ, Allen KJ et al. (2016) The impact of timing of introduction of solids on infant body mass index. J Pediatr 179, 104-110 e101.

16. Laving AR, Hussain SR \& Atieno DO (2018) Overnutrition: does complementary feeding play a role? Ann Nutr Metab 73, Suppl. 1, 15-18.

17. Wang J, Wu Y, Xiong G et al. (2016) Introduction of complementary feeding before 4 months of age increases the risk of childhood overweight or obesity: a meta-analysis of prospective cohort studies. Nutr Res 36, 759-770.

18. World-Health-Organization (2010) Indicators for Assessing Infant and Young Child Feeding Practices. Part 2. Measurement. Geneva: World Health Organization.

19. World-Health-Organization (2008) Indicators for Assessing Infant and Young Child Feeding Practices. Part 1: Definitions. Geneva: World Health Organization.

20. Carballo M, Khatoon N, Maclean EC et al. (2017) Infant and young child feeding patterns in Kuwait: results of a cross-sectional survey. Public Health Nutr 20, 2201-2207.
21. Kuwait_Nutrition_Surveillance_System (2017) 2017 Annual Report. FaN Administration. Kuwait: Ministry of Health.

22. Horta BL, Loret de Mola C \& Victora CG (2015) Long-term consequences of breastfeeding on cholesterol, obesity, systolic blood pressure and type 2 diabetes: a systematic review and meta-analysis. Acta Paediatr 104, 30-37.

23. de Onis M \& Lobstein T (2010) Defining obesity risk status in the general childhood population: which cut-offs should we use? Int J Pediatr Obes 5, 458-460.

24. Aris IM, Rifas-Shiman SL, Li LJ et al. (2018) Association of weight for length vs body mass index during the first 2 years of life with cardiometabolic risk in early adolescence. JAMA Netw Open 1, e182460.

25. Roy SM, Fields DA, Mitchell JA et al. (2019) Body mass index is a better indicator of body composition than weight-forlength at age 1 month. $J$ Pediatr 204, 77-83.e71.

26. Roy SM, Spivack JG, Faith MS et al. (2016) Infant BMI or weight-for-length and obesity risk in early childhood. Pediatrics 137, pii: e20153492.

27. Jones AD, Ickes SB, Smith LE et al. (2014) World Health Organization infant and young child feeding indicators and their associations with child anthropometry: a synthesis of recent findings. Matern Child Nutr 10, 1-17.

28. CDC (2018) Breastfeeding Report Card. https://www.cdc. gov/breastfeeding/data/reportcard.htm (accessed May 2019).

29. UNICEF (2018) Infant and Young Child Feeding. https://data. unicef.org/topic/nutrition/infant-and-young-child-feeding/ (accessed November 2018).

30. Beake S, Bick D, Narracott C et al. (2017) Interventions for women who have a caesarean birth to increase uptake and duration of breastfeeding: a systematic review. Matern Child Nutr 13(4), doi: 10.1111/mcn.12390.

31. Ye J, Betran AP, Guerrero Vela M et al. (2014) Searching for the optimal rate of medically necessary cesarean delivery. Birth 41, 237-244.

32. Prior E, Santhakumaran S, Gale C et al. (2012) Breastfeeding after cesarean delivery: a systematic review and metaanalysis of world literature. Am J Clin Nutr 95, 1113-1135.

33. McFadden A, Baker L \& Lavender T (2009) Exploration of factors influencing women's breastfeeding experiences following a caesarean section. Evid Based Midwif 7, 64 .

34. MOH (2013) Annual Health Report 2013. Kuwait: Ministry of Health.

35. WHO (2003) WHO Global Data Bank on Infant and Young Child Feeding (IYCF). https://www.who.int/nutrition/ databases/infantfeeding/countries/che.pdf?ua=1 (accessed September 2019)

36. CSB (2013) Household income and expendeture survey 2013. https://www.csb.gov.kw/Pages/Statistics_en?ID=16\&Parent CatID $=\% 201$ (accessed May 2019)

37. Jiang M, Foster E, Gibson-Davis C (2010) The effect of WIC on breastfeeding: a new look at an established relationship. Child Youth Serv Rev 32, 264-273.

38. Balogun OO, O'Sullivan EJ, McFadden A et al. (2016) Interventions for promoting the initiation of breastfeeding. Cochrane Database Syst Rev issue 11, CD001688.

39. EFSA (2009) EFSA Panel on Dietetic Products, Nutrition and Allergies (NDA). Scientific opinion on the appropriate age for introduction of complementary feeding of infants. EFSA J 7, 1423.

40. Fewtrell M, Bronsky J, Campoy Cet al. (2017) Complementary feeding: a position paper by the european society for paediatric gastroenterology, hepatology, and nutrition (ESPGHAN) committee on nutrition. J Pediatr Gastroenterol Nutr 64, 119-132.

41. Kramer MS \& Kakuma R (2012) Optimal duration of exclusive breastfeeding. Cochrane Database Syst Rev issue 8, CD003517.

42. White JM, Begin F, Kumapley R et al. (2017) Complementary feeding practices: current global and regional estimates. Matern Child Nutr 13, Suppl. 2, doi: 10.1111/mcn.12505. 
43. Clayton HB, Li R, Perrine CG et al. (2013) Prevalence and reasons for introducing infants early to solid foods: variations by milk feeding type. Pediatrics 131, e1108-e1114.

44. Ruel MT (2017) Measuring infant and young child complementary feeding practices: indicators, current practice, and research gaps. Nestle Nutr Inst Workshop Ser 87, $73-87$.

45. Mallard SR, Houghton LA, Filteau S et al. (2014) Dietary diversity at 6 months of age is associated with subsequent growth and mediates the effect of maternal education on infant growth in urban Zambia. J Nutr 144, 1818-1825.

46. Krasevec J, An X, Kumapley R et al. (2017) Diet quality and risk of stunting among infants and young children in low- and middle-income countries. Matern Child Nutr 13, Suppl. 2, doi: $10.1111 / \mathrm{mcn} .12430$.

47. Marriott BP, White AJ, Hadden L et al. (2010) How well are infant and young child World Health Organization (WHO) feeding indicators associated with growth outcomes? An example from Cambodia. Matern Child Nutr 6, 358-373.
48. Marriott BP, White A, Hadden L et al. (2012) World Health Organization (WHO) infant and young child feeding indicators: associations with growth measures in 14 low-income countries. Matern Child Nutr 8, 354-370.

49. Aryastami N, Shankar A, Kusumawardani N et al. (2017) Low birth weight was the most dominant predictor associated with stunting among children aged 12-23 months in Indonesia. BMC Nutr 3, 16.

50. Rahman MS, Howlader T, Masud MS et al. (2016) Association of low-birth weight with malnutrition in children under five years in Bangladesh: do mother's education, socio-economic status, and birth interval matter? PLOS ONE 11, e0157814.

51. Pearce J, Taylor MA \& Langley-Evans SC (2013) Timing of the introduction of complementary feeding and risk of childhood obesity: a systematic review. Int J Obes 37, 1295-1306.

52. Grote V, Theurich M, Luque V et al. (2018) Complementary feeding, infant growth, and obesity risk: timing, composition, and mode of feeding. Nestle Nutr Inst Workshop Ser $\mathbf{8 9}$, 93-103. 